\title{
Combining experimentation and reflection techniques in behavioral competency development programs: A learning approach based on journaling and peer coaching
}

\author{
Laura Cortellazzo, Sara Bonesso, Fabrizio Gerli \\ Department of Management, Ca' Foscari University of Venice, Italy.
}

\begin{abstract}
Behiavioral competencies are key determinants of individual performance and literature has recently started to devote attention on those methodological approaches that can effectively promote their development. According to Dewey, individuals do not learn from experience, but they learn from reflecting on experience. In this paper, we draw on the Dewey's idea and we investigate if reflective practices through journaling and peer coaching can improve the learning experience of individuals engaged in a competency development program. After introducing the prior research that emphasized the positive impact of these two reflective techniques, the paper illustrates how journaling and peer coaching has been introduced as a part of a competency development program. Preliminary insights from the empirical case show that self-directed learning requires a reflection process that helps individuals to better understand their current behavior, their progresses, and opportunities for change. Journaling was found especially useful to increase one's selfawareness and self-confidence, whereas peer coaching allowed students create a social bond, share their experiences and receive a direct feedback from a peer. The paper also illustrates the limits of these reflective practices, discussing the interventions that can be implemented to maximize their learning benefits.
\end{abstract}

Keywords: emotional and social competencies; reflective journaling; peer coaching; experiential leaderning. 


\section{Introduction}

The current economic environment, characterized by increasing competition, flexibility, and continuous rapid change, has led organizations to look for employees with personal characteristics that go beyond their mere technical ability. Nowadays, people who want to enter the labor market are required to show a set of emotional and social competencies (Azevedo et al. 2012; LinkedIn, 2019) that enable them to pursue effectiveness (Brown, et al., 2003; Emmerling and Cherniss, 2013). Adopting a behaviorist approach to emotional intelligence (Boyatzis, 2016), we define emotional and social competencies as "related but different sets of behavior organized around an underlying construct, which we call the 'intent”' (Boyatzis, 2009: 750).

Scholars maintain that the development of these competencies requires an approach that is different from traditional methods based on passive accumulation of knowledge that have traditionally been offered by higher education institutions (Garcia-Aracil and Van der Velden, 2008). The development of emotional and social competencies should be based on active learning, stimulation of relationships and cooperation (Garcia-Aracil and Van der Velden, 2008), in which experience plays a critical role (Kolb, 1984).

By involving participants in a process of reflection, interactive engagement, and practice, experiential learning techniques stimulate the cognitive, behavioral, and emotional dimensions of learning and behavioral change that are necessary to acquire emotional and social competencies (Hoover et al., 2010). Experiential learning conceives learning as a holistic process in which the person is called upon to think, feel, perceive and behave in the interaction with the environment (Kolb, 1984). According to experiential learning theory, the ideal learning cycle is a recursive process in which concrete experiences represent the basis for reflection and observation (Kolb and Kolb, 2005). Reflection allows individuals attach meanings to their experiences, creating frameworks of knowledge, which in turn transforms the action patterns (Yeo and Marquardt, 2015).

Although practitioners have often translated the principles of experiential learning theory simply in the provision of contexts in which students can try out new things, the literature clarifies that experiences alone do not promote the development of the person as much as the meaning that individuals derive from such events (Ligon and Hunter, 2010). According to Kolb (1984), taking experience seriously means honoring and valuing people's subjective sense-making and reflection, which represent a substantial feature of learning (Dewey, 1933).

The ability to reflect refers to how effectively individuals can learn from their personal experiences (Boud et al., 1985). It facilitates the process of analyzing the various components of the experience and convert it into learning, through the construction of a meaning. 
In this paper, we thus overcome the idea that the experience alone is enough to drive the acquisition of emotional and social competencies, and explore the role that personal reflection may have in this process. We will focus on two instruments adopted to enhance personal reflection and convey behavioral change, namely journaling and peer coaching, and we will present a case study that illustrates the benefits and challenges of the application of the two instruments for emotional and social competency development.

\section{Theoretical background}

\subsection{Journaling}

Journaling is one of the most common tools used to foster individuals' practice of reflection due to its ease of implementation and the potential depth of the outcome (Roberts, 2008). It consists of the daily, or weekly, report of experiences from which thoughts, feelings, ideas, reactions arise (Montagna et al., 2013). Reflective writing is the expression on paper, or on the screen, of some mental processes of reflection. Writing things down allows the individual to distance him/herself from what he/she has experienced and examine the situation from an external point of view (Jefferson et al., 2014). This facilitates the individual in giving a structure to the experience, linking facts together and searching for the deeper meanings of the events taken into consideration. Moreover, it allows for a meta-analysis of experiences, by giving the individual the opportunity to integrate behavioral and emotional patterns that follow one another in the daily experiece (Jefferson et al., 2014).

\subsection{Peer coaching}

Peer coaching is a confidential process by which two peers work together to reflect on current practices, expand, refine and build new skills, share ideas, and teaching each other (Robbins, 1991). Jackson (2004) proposes that coaching is intrinsically a reflection effort, as coaches are able to ask questions that spur the coachee critical reflection (Robertson, 2005). Experiential learning advocates the value of consulting with knowledgeable peers (Schön, 1983), as it allows peers to assist each other in learning and drawing insights into personal behavior (Parker et al. 2008). Peer coaching is a type of developmental relationship that needs to be characterized by positive inclination, authenticity and mutual trust to be effective (Rogers, 1973). Compared to other developmental relationships, peer coaching differs for being characterized by the mutuality and reciprocity of the process.

Previous studies showed that peer coaching had a positive influence on students' personal development. For instance Parker et al. (2008), found a positive relationship between peer coching and leadership development in a group of MBA students. 


\section{The adoption of journaling and peer coaching for competency development}

To better understand the effectiveness of journaling and peer-coaching for the development of emotional and social competencies, and highlight the advantages and limitations of the two tools, we conducted an analysis on a group of Master students participating to the elective course "Emotional competencies and personal development". The aim of this course is to encourage students' development of emotional and social competencies through a selfdirected learning methodology. During the course, student learn what emotional and social competencies are, reflect on their ideal future self, undertake a multi-rater assessment of their emotional and social competencies and finally define which are the two or three competencies they would like to improve with priority.

During the four months that follow the end of the course, students were asked to engage in the experimentation of new behaviors in real-life contexts aimed at improving the competencies defined as learning objectives. They were asked to complement their learning process using the tools of journaling and peer coaching. Specifically, they were asked to write a journal at least twice a week and perform peer coaching sessions at least once a month. They were provided with one form to fill in per each activity to facilitate their reflection process. In the journaling form they were asked to reflect upon: i) the situation in which they practiced the emotional or social competency; ii) the specific behaviors adopted; iii) the positive and negative outcomes of their behaviors they perceived or other people expressed as a feedback; iv) emotions felt, difficulties encountered, and areas of improvement. The peer coaching form consisted of a first reflection on the main topics discussed during the session, followed by a question on the perceived benefits of the session, and on the questions that helped the individual carry out a more in depth reflection on his/her learning experiences.

Both the journaling and peer coaching forms were analyzed through a thematic analysis in order to explore the evolution of the development path students were undertaking.

After the four months, a survey has been carried out in which we asked students to what extent the activities of journaling and peer coaching contributed to become aware of the progresses made in the improvement of the emotional or social competency, to what extent they helped the student identify the behaviors that lead to positive outcomes, the behaviors that generate negative outcomes, and the way to change in order to achieve more positive results in the following learning experience. The scale used ranged from 1 (totally disagree) to 7 (totally agree). Open questions were included to investigate the students' perception on the effectiveness of journaling and peer coaching as instruments to pursue competency development, and the difficulties students encountered during their use. 


\subsection{Results}

The initial sample participating to the course was composed by 51 Master students, of which $70 \%$ females and 30\% males. Seventy-one percent of the initial sample engaged in the journaling and peer coaching actitvities.

The majority of the sample completed the journaling activity on average once a week, $37 \%$ percent completed the activity on average twice a week, and the $4 \%$ engaged in the activity more than twice a week. From a qualitative analysis of the content of students' writings, it emerges that journal reflection enhanced an increasing self-awareness troughout time. Three main phases can be identified. In the initial phase, the writings brings together a contraposition between hesitation and fears and a great desire to improve. For instance, students reported: "I hate myself when I am under stress, I am the worst, I am not empathic, I am selfish and grumpy", but also "I felt I was ready to react, to start changing as soon as possible". The intermediate phase is characterized by greater awareness and willingness to achieve improvement. Comments mainly describe situations in which despite the small difficulties, students feel they can achieve results, they valorize their own stregths and believe in themselves. The third phase describes a consolidation of the awareness. They become aware of their progresses and continue to challenge themselves. Ideed, in the final survey, students identified benefits of the journaling activity that include: developing higher awareness of their learning path; higher concentration; higher intrinsic motivation to development; improvement of well-being. The main difficulties encountered regard the need for perseverance to maintain a certain frequency of writing, shyness in writing down some negative experiences, and describing the emotions felt. From a methodological point of view, some students felt the scheme provided was too rigid, and they perceived a sense of obligation that devalued the activity and the desire to complete it.

As for the peer coaching activity, students grouped in couples performed a coaching session on average once a month. Students appreciated both elements related to their role as a coach and as a coachee. As a coach, students perceived an improvement in their active listening, empathy, and in their being supportive. As a coachee, they acquired new stimuli thanks to the sharing of different development methods for the same competency and the discussion of different points of view. They felt the effective exchange of experiences, of progreses and failures enhanced the awareness on their development. Students unanimously declared they created a good feeling with their peer, which consistently with theory, leads to a trusting relationship in which people express their thoughts and feelings without fear of judgment. The main obstacles encountered concerned the fit of agendas to find a moment to talk. Secondly, being constant both in the frequency of appoinments and in the level of enthusiasm was found challenging. Some students also felt not good enough in asking the right questions. 
Concerning the quantitative assessment of the efficacy of the journaling and peer coaching instruments for competency development, $78 \%$ of the sample agreed (rates from 5 to 7 ) that journaling helped them become more aware of their progresses, a slightly higher percentage was found for peer coaching (81\%). The influence of journaling on the understanding of effective and non effective behaviors was rated as positive by $71 \%$ and $50 \%$ of the sample respectively. As for peer coaching, $83 \%$ and $74 \%$ of the sample agreed with the helpfulness of peer coaching in identifying effective and non effective behaviors. $75 \%$ of the students agreed journaling helped them identify ways to modify their behaviors to improve their competencies, a slightly lower percentage was found for peer caching (70\%).

\section{Discussion}

This case analysis advances the understanding of how journaling and peer coaching can be adopted in an emotional and social competency development program in order to enhance the students' engagement in an experiencial learning cycle. To improve emotional and social competenecies, experiencial learning techniques are required. However, beside undertaking the experience itself, we argue that in order to maximize the learning from experience, students should be accompanied in their reflection process. To do it, journaling and peer coaching were found to be positively valued by students, who perceived the two tools helped them better understand their current behavior, their progresses, and opportunitites for change.

Journaling was found especially useful to increase one's self-awareness and self confidence. However, the number of journals to write in a week was considered too demanding and led to a higher dropping rate. From a methodological point of view, the tradeoff between need for regularity in writing and level of commitment need to be found. Moreover, someone considered the predefined schema to fill in too rigid to freely express the sense-making of their experiences.

Peer coaching resulted to be generally more appreciated, as besides the benefits in terms of self-reflection, it allowed students create a social bond, share their experiences and receive a direct feedback from a peer.

The case provides also evidence of the effective integration between classroom activities and self-directed learning. The first provides the theoretical bases to understand how to direct one's improvement. Afterwards, students need to be provided tools that can be used in their everyday life that can ease the process of continuous learning. 


\section{Limitations and future directions}

The present study presents some limitations that can be addressed by future research. First, the study is limited in terms of sample size. Future developments of this research will overcome this issue by addressing different cohorts involved in the process of emotional and social competency development. Second, the method adopted is coherent with the explorative nature of this study, but limited in the ability to empirically test the influence of the journaling and peer coaching tools on competency development. Thus, future directions for research include the adoption of a quasi-experimental design that could provide further insight on the effects of journaling and peer coaching in the improvement of emotional and social competencies.

\section{References}

Azevedo, A., Apfelthaler G., \& Hurst, D. (2012). Competency development in business graduates: An industry-driven approach for examining the alignment of undergraduate business education with industry requirements. The International Journal of Management Education, 10, 12-28.

Boud, D., Keogh, R., \& Walker, D. (1985). What is reflection in learning? In D. Boud, R. Keogh, \& D. Walker (Eds), Reflection: Turning experience into learning (pp. 7-17). London: Kogan Page

Boyatzis, R.E. (2009). Competencies as a behavioral approach to emotional intelligence. Journal of Management Development, 28(9), 749-770.

Boyatzis, R.E. (2016). Commentary on Ackley (2016): updates on the ESCI as the behavioral level of emotional intelligence. Consulting Psychology Journal: Practice and Research, 68(4), 287-293.

Brown, C., George-Curran, R., \& Smith, M.L. (2003). The role of emotional intelligence in the career commitment and decision-making process. Journal of Career Assessment, 11, 379-392.

Dewey, J. (1933). How we think DC Heath. Boston, MA, 1933.

Emmerling, R.J., \& Cherniss, C. (2003). Emotional intelligence and the career choice process. Journal of Career Assessment, 11, 153-167.

Garcia-Arracil, A., \& Van der Velden, R. (2008). Competencies for young European higher education graduates: labor market mismatches and their payoffs. Higher Education, 55, 219-239.

Hoover, J.D., Giambatista, R.C., Sorenson, R.L., \& Bommer, W.H. (2010). Assessing the Effectiveness of Whole Person Learning Pedagogy in Skill Acquisition. Academy of Management Learning and Education, 9(2), 192-203.

Jackson, P. (2004). Understanding the experience of experience: a practical model of reflective practice for coaching. International Journal of Evidence Based Coaching and Mentoring, 2(1), 57-67. 
Jefferson J.K., Martin, I.H., \& Owens, J. (2014). Leader development through reading an reflection. Journal of Leadership Studies, 8(2), 67-75.

Kolb, D.A. (1984). Experiential learning: experience as the source of learning and development. Englewood Cliffs, NJ: Prentice Hall.

Kolb, A.Y., \& Kolb, D.A. (2005). Learning styles and learning spaces: enhancing experiential learning in higher education. Academy of Management Learning \& Education, 4(2), 193-212.

Ligon, G.S., \& Hunter, S.T. (2010). Putting the development into experiential development. Industrial and Organizational Psychology, 3, 28-32.

LinkedIn (2019) Global Talent Trends. The 3 trends transforming your workplace. Retrieved from: https://business.linkedin.com/content/dam/me/business/en-us/talentsolutions/resources/pdfs/global_talent_trends_2019_emea.pdf

Montagna, S.B., Dimonte, V., \& Garrino, L. (2013). The reflective journal: A tool for enhancing experience-based learning in nursing students in clinical practice. Journal of Nursing Education and Practice 3(3), 102-111.

Parker, P., Hall, D.T., \& Kram, K.E. (2008). Peer coaching: a relational process for accelerating career learning. Academy of Management Learning \& Education, 7(4), 487503.

Roberts, C. (2008). Developing future leaders: The role of reflection in the classroom . Journal of Leadership Education, 7(1), 116-130.

Rogers, C. (1973). Characteristics of a helping relationship. In D. E. B. W. G. Bennis, E. H. Schein, \& F. I. Steele (Eds.), Interpersonal dynamics (3rd ed., pp. 223-236). Homewood, IL: Irwin-Dorsey.

Robbins, P. (1991). How to plan and implement a peer coaching program. Association for Supervision and Curriculum Development. Retrived from https://eric.ed.gov/?id=ED337881

Robertson, K. (2005). Active listening: more than just paying attention. Australian Family Physician, 34(12), 1053-1055.

Schön, D.A. (1983). The reflective practitioner: How professionals think in action. New York: Basic Books.

Yeo, R.K., \& Marquardt, M.J. (2015). (Re)interpreting action, learning, and experience: integrating action learning and experiential learning. Human Resource Development Quarterly, 26(1), 81-107. 